1 Thrombosis and Haemophilia Centre, Guy's and St Thomas' NHS Foundation Trust, London SE1 7EH, UK

2 School of Medical Sciences, University of Campinas, Campinas, São Paulo, Brazil

3 Maternal-Fetal Medicine Service, National Women's Health, Auckland City Hospital, Auckland, New Zealand

4 Department of Cardiovascular Surgery, School of Medicine, University of Uskudar, Istanbul, Turkey

Correspondence to: B H Hunt Beverley.hunt@gstt.nhs.uk Cite this as: BMJ 2021;372:n487 http://dx.doi.org/10.1136/bmi.n487 Published: 19 February 2021

\title{
Prophylactic anticoagulation for patients in hospital with covid-19
}

\author{
Risk-benefit balance may depend on illness severity
}

\section{Beverley J Hunt, ${ }^{1}$ Erich V De Paula, ${ }^{2}$ Claire McLintock, ${ }^{3}$ Mert Dumantepe ${ }^{4}$}

Most people with covid-19 have mild disease, but after 5-10 days an important minority develop pneumonia and require hospital admission to treat hypoxia. This group is in a marked prothrombotic state and has high rates of hospital associated venous thromboembolism. ${ }^{1}$

Early in the pandemic, deep vein thromboses and high rates of occlusive changes on computed tomography pulmonary angiograms were seen in at least $70 \%$ of patients with severe covid-19. Although these were initially thought to be pulmonary emboli, many patients had only isolated segmental and subsegmental changes, probably caused by the in situ thrombosis (termed immunothrombosis) that occurs in all forms of acute respiratory distress syndrome, ${ }^{23}$ although more commonly with covid-19. 45

Randomised controlled trials show that drug based thromboprophylaxis with low molecular weight heparin (LMWH) reduces the risk of hospital associated venous thromboembolism by about $50 \%$ in medical and critically ill inpatients. ${ }^{6}$ Risk factors that qualify patients for thromboprophylaxis are reduced mobility; acute infective illness, such as pneumonia; and admission for critical care. Thus, adults admitted to hospital with covid-19 pneumonia should automatically receive thromboprophylaxis.

At the beginning of the pandemic, it became apparent that, unlike the National Health Service in England, several countries did not mandate risk assessment for venous thromboembolism and were not routinely using thromboprophylaxis, even for critically ill patients with covid-19. An early, small observational study showed heparin improved mortality in critically ill patients with covid-19, ${ }^{7}$ and this finding prompted many critical care units to start using thromboprophylaxis. In contrast, some clinicians who were already prescribing standard dose thromboprophylaxis with LMWH (such as dalteparin 5000 IU once daily) increased the dose to an intermediate (500o IU twice daily) or even therapeutic level (200 IU/kg). Early national and international guidance based on expert opinion has been inconsistent. $^{8-11}$

Good data to guide thromboprophylaxis with LMWH in patients admitted to hospital with covid-19 pneumonia is urgently needed, and the linked retrospective study by Rentsch and colleagues (doi:10.1136/bmj.n311) confirms that thromboprophylaxis is associated with improved mortality in patients admitted to hospital with covid-19. ${ }^{12}$

At the same time, an interim analysis of combined data from three separate randomised controlled trials-the anticoagulation arm of the platform trial REMAP-CAP, ATTACC, and ACTIV4a-recently reported the impact of different doses of anticoagulation on outcomes. The trials used similar protocols, run in parallel. According to details provided by press release and on Twitter, the trio compared prophylactic heparin at therapeutic doses (either LMWH or unfractionated heparin) with local standard care in patients admitted to hospital with severe or moderate covid-19. In all three trials, heparin was given for 14 days or until hospital discharge (or after stopping supplemental oxygen in ATTACC), whichever was sooner. ${ }^{13}$ The primary outcome was a combination of mortality and the number of days free from organ support in critical care (including receipt of mechanical ventilation, vasopressors, extracorporeal membrane oxygenation, or high flow nasal oxygen) at day 21 . The trials contained more men than women and most were aged 50-79 years, although more than 100 were older than 80 years.

In December, the joint data safety monitoring board paused the trials for participants with severe covid-19 because those receiving therapeutic doses of heparin showed increased mortality relative to controls and greater requirement for oxygen support (odds ratio for survival or decreased need for organ support 0.76 ( $95 \%$ confidence interval o.6 to 0.97). Risk of major bleeding was also increased, from $1.8 \%$ in controls receiving standard care to $3.7 \%$ in those receiving anticoagulation.

In contrast, on 21 January, the arms recruiting patients with moderate disease were also paused, but this time owing to an apparent superiority of anticoagulation at therapeutic doses. The results were analysed according to whether D dimer levels were low or high at presentation, but results were similar, suggesting that baseline $\mathrm{D}$ dimer tests are of no value in assessing thrombotic risk in patients admitted to hospital with covid-19 pneumonia. Those with moderate disease receiving prophylactic anticoagulation at therapeutic doses were significantly more likely than controls to achieve the primary outcome of survival or reduced requirement for organ support (low D dimer levels: median odds ratio 1.57 (95\% confidence interval 1.14 to 2.19); high D dimer levels 1.53 (1.09 to 2.17)).

Among patients who were moderately ill at baseline, major bleeding was seen in $0.9 \%$ of controls receiving standard care and $1.6 \%$ of those receiving anticoagulation at therapeutic doses.

These interim results were widely available before peer review and formal publication. Whether early non-peer reviewed data should ever direct a change in practice or guidelines remains an open question. 
If the findings are confirmed, further research should consider whether benefit from therapeutic dose LMWH or unfractionated heparin is confined to patients with moderate covid-19; whether the apparent benefit of heparins could be related to their anti-inflammatory and antiviral effects, not just to their anticoagulant effect ${ }^{14}$; whether heparin influences rates of immunothrombosis; and finally, the relative effects of standard versus intermediate thromboprophylaxis in severe covid-19, and intermediate versus therapeutic thromboprophylaxis in moderate covid-19.

The risk of hospital associated venous thromboembolism for medical inpatients is greatest in the first 90 days post-discharge, ${ }^{9}$ and many units are using unlicensed extended thromboprophylaxis with LMWH or direct acting oral anticoagulants for patients discharged after covid-19. ${ }^{8} 9$ Recent retrospective data showing low rates of hospital associated venous thromboembolism post-discharge are reassuring, ${ }^{15^{-17}}$ but randomised trials formally evaluating the need for extended thromboprophylaxis are now required.

Competing interests: The BMJ has judged that there are no disqualifying financial ties to commercial companies.

The authors declare the following other interests: BJH sits on the REMAP-CAP covid-19 therapeutic anticoagulation therapy domain governance committee.

The BMJ policy on financial interests is here: https://www.bmj.com/sites/default/files/attachments/resources/2016/03/16-current-bmj-education-coi-form.pdf."

Provenance and peer review: Commissioned; not externally peer reviewed.

1 Jiménez D, García-Sanchez A, Rali P, etal. Incidence of venous thromboembolism and bleeding among hospitalized patients with COVID-19: a systematic review and meta-analysis. Chest 2020;17.pmid: 33217420

2 Desborough MJR, Doyle AJ, Griffiths A, Retter A, Breen KA, Hunt BJ. Image-proven thromboembolism in patients with severe COVID-19 in a tertiary critical care unit in the United Kingdom. Thromb Res 2020;193:1-4. doi: 10.1016/j.thromres.2020.05.049 pmid: 32485437

3 Engelmann B, Massberg S. Thrombosis as an intravascular effector of innate immunity. Nat Rev Immunol 2013;13:34-45. doi: 10.1038/nri3345 pmid: 23222502

4 Doyle AJ, Hunt BJ, Sanderson B, etal. A Comparison of Thrombosis and Haemorrhage Rates in Patients with Severe Respiratory Failure due to COVID-19 and Influenza requiring Extracorporeal Membrane Oxygenation. Crit Care 2021; (In press).

5 Tzotzos SJ, Fischer B, Fischer H, Zeitlinger M. Incidence of ARDS and outcomes in hospitalized patients with COVID-19: a global literature survey. Crit Care 2020;24:516. doi: 10.1186/s13054-020-03240-7 pmid: 32825837

6 Venous thromboembolism in over 16s: reducing the risk of hospital-acquired deep vein thrombosis or pulmonary embolism. NICE guideline. https://www.nice.org.uk/guidance/ng89 (accessed 10 Feb 2021).

7 Tang N, Bai H, Chen X, Gong J, Li D, Sun Z. Anticoagulant treatment is associated with decreased mortality in severe coronavirus disease 2019 patients with coagulopathy. J Thromb Haemost 2020;18:1094-9. doi: 10.1111/jth.14817 pmid: 32220112

8 COVID-19 rapid guideline: reducing the risk of venous thromboembolism in over $16 \mathrm{~s}$ with COVID-19. NICE guideline. https://www.nice.org.uk/guidance/ng186 (accessed 10 Feb 2021).

9 Spyropoulos AC, Levy JH, Ageno W, etalSubcommittee on Perioperative, Critical Care Thrombosis, Haemostasis of the Scientific, Standardization Committee of the International Society on Thrombosis and Haemostasis. Scientific and Standardization Committee communication: Clinical guidance on the diagnosis, prevention, and treatment of venous thromboembolism in hospitalized patients with COVID-19. J Thromb Haemost 2020;18:1859-65. doi: 10.1111/jth.14929 pmid: 32459046

10 Cuker A, Tseng EK, Nieuwlaat R, etal. American Society of Hematology 2021 guidelines on the use of anticoagulation for thromboprophylaxis in patients with COVID-19. Blood Adv 2021;5:872-88. doi: 10.1182/bloodadvances.2020003763 pmid: 33560401

11 COVID-19 Clinical management: living guidance. https://www.who.int/publications/i/item/WHO2019-nCoV-clinical-2021-1 (accessed 10 Feb 2021).

12 Rentsch CT, Beckman JA, Tomlinson L, etal. Early initiation of prophylactic anticoagulation for prevention of coronavirus disease 2019 mortality in patients admitted to hospital in the United States: cohort study. BMJ 2021;372:n311. doi: 10.1136/bmj.n311 pmid: 33574135

13 ATTACC. ACTIV-4a \& REMAP-CAP multiplatform RCT - Results of interim analysis. https://www.attacc.org/presentations (accessed 10 Feb 2021).

14 Hippensteel JA, LaRiviere WB, Colbert JF, Langouët-Astrié CJ, Schmidt EP. Heparin as a therapy for COVID-19: current evidence and future possibilities. Am J Physiol Lung Cell Mol Physiol 2020;319:L211-7. doi: 10.1152/ajplung.00199.2020 pmid: 32519894
15 Roberts LN, Whyte MB, Georgiou L, etal. Postdischarge venous thromboembolism following hospital admission with COVID-19. Blood 2020;136:1347-50. doi: 10.1182/blood.2020008086 pmid: 32746455

16 Salisbury R, lotchkova V, Jaafar S, etal. Incidence of symptomatic, image-confirmed venous thromboembolism following hospitalization for COVID-19 with 90-day follow-up. Blood Adv 2020;4:6230-9. doi: 10.1182/bloodadvances.2020003349 pmid: 33351117

17 Doyle AJ, Thomas W, Retter A, etal. Updated hospital associated venous thromboembolism outcomes with 90-days follow-up after hospitalisation for severe COVID-19 in two UK critical care units. Thromb Res2020;196:454-6. doi: 10.1016/j.thromres.2020.10.007 pmid: 33065410

This article is made freely available for use in accordance with BMJ's website terms and conditions for the duration of the covid-19 pandemic or until otherwise determined by BMJ. You may use, download and print the article for any lawful, non-commercial purpose (including text and data mining) provided that all copyright notices and trade marks are retained. 